\title{
Low Dose Administration of Glutamate Triggers a Non-Apoptotic, Autophagic Response in PC12 Cells
}

\author{
Eleni Stamoula ${ }^{a}$ Theofanis Vavilis ${ }^{a}$ Eleni Aggelidou ${ }^{a}$ Aikaterini Kaidoglou ${ }^{b}$ \\ Angeliki Chevac Kyriakos Mellidis ${ }^{d} \quad$ Antigone Lazou $^{d}$ Costas Haitoglou ${ }^{e}$ \\ Maria Albania Aristeidis Kritis ${ }^{\mathrm{a}}$
}

aLaboratory of Physiology, Department of Physiology and Pharmacology, School of Medicine, Faculty of Health Sciences, Aristotle University of Thessaloniki, Thessaloniki, 'Laboratory of Histology, Embryology and Anthropology, School of Medicine, Faculty of Health Sciences, Aristotle University of Thessaloniki, Thessaloniki, 'Department of Pathology, General Hospital of Thessaloniki "G. Papanikolaou", Thessaloniki, 'Laboratory of Physiology, School of Biology, Faculty of Sciences, Aristotle University of Thessaloniki, Thessaloniki, eLaboratory of Biochemistry, Department of Biochemistry, School of Medicine, Faculty of Health Sciences, Aristotle University of Thessaloniki, Thessaloniki, Greece

\section{Key Words}

Glutamate $\cdot$ Chaperones $\cdot$ Stress $\cdot$ Excitotoxicity $\cdot$ autophagy

\begin{abstract}
Background/Aims: Increasing amounts of the neurotransmitter glutamate are associated with excitotoxicity, a phenomenon related both to homeostatic processes and neurodegenerative diseases such as multiple sclerosis. Methods: PC12 cells (rat pheochromocytoma) were treated with various concentrations of the non-essential amino acid glutamate for 0.5-24 hours. The effect of glutamate on cell morphology was monitored with electron microscopy and haematoxylin-eosin staining. Cell survival was calculated with the MTT assay. Expression analysis of chaperones associated with the observed phenotype was performed using either Western Blotting at the protein level or qRT-PCR at the mRNA level. Results: Administration of glutamate in PC12 cells in doses as low as $10 \mu \mathrm{M}$ causes an up-regulation of GRP78, GRP94 and HSC70 protein levels, while their mRNA levels show the opposite kinetics. At the same time, GAPDH and GRP75 show reduced protein levels, irrespective of their transcriptional rate. On a cellular level, low concentrations of glutamate induce an autophagy-mediated pro-survival phenotype, which is further supported by induction of the autophagic marker LC3. Conclusion: The findings in the present study underline a discrete effect of glutamate on neuronal cell fate depending on its concentration. It was also shown that a low dose of glutamate orchestrates a unique expression signature of various chaperones and induces cell autophagy, which acts in a neuroprotective fashion.
\end{abstract}




\section{Cellular Physiology Cell Physiol Biochem 2015;37:1750-1758 \begin{tabular}{l|l|l}
\hline DOI: 10.1159/000430250 & (C) 2015 S. Karger AG, Basel
\end{tabular} \begin{tabular}{l|l|l|l|l|l} 
and Biochemistry Published online: November 13, 2015 & www.karger.com/cpb \\
\cline { 1 - 2 }
\end{tabular}

\section{Introduction}

Glutamate is an essential excitatory neurotransmitter that is produced by the tricarboxylic acid cycle or as a product of glutamine deamination and plays a significant role in essential neural functions such as learning, memory, long-term potentiation and synaptic plasticity $[1,2]$. Its extracellular concentration needs to be maintained at low levels since its excessive accumulation in the extracellular area leads to a disease-related state known as excitotoxicity, through over-activation of glutamate receptors and the concomitant toxic depolarisation of neurons [3]. Glutamate receptors, which are divided into metabotropic and ionotropic, drive excitotoxicity through the regulation of calcium influx, the production of NO and the orchestration of classical (caspase-mediated) and novel (GAPDH/Siah 1) apoptotic pathways [4]. Moreover, excessive glutamate concentration in the extracellular area promotes intracellular toxicity through reverse operation of the cysteine/glutamate antiporter (Xc-), a phenomenon called oxidative glutamate toxicity [5]. Glutamate-associated cell toxicity has been related to various neurodegenerative pathologies such as Huntington disease, Amyotrophic lateral sclerosis, stroke and brain trauma; hence, fine-tuning of its extracellular levels is important for the maintenance of neural homeostasis [6].

Glutamate-induced excitotoxicity is related to endoplasmic reticulum stress [7], which can trigger the unfolded protein response (UPR), a dynamic signalling network that restores proteostasis. UPR is often the leading cause of various neurodegenerative diseases and serves as an active field of interest for pharmacological intervention [8]. Recent studies have linked UPR to autophagy-related neuronal cell death, a fact that is however still being debated. Accumulative evidence supports a significant role of various chaperones either in UPR per se or in UPR-mediated autophagy. For example, GRP78 serves as a key player in autophagy activated as a protective mechanism that maintains ER homeostasis [9], while its close partner, GRP94, the endoplasmic member of the HSP90 family of stress-related proteins, orchestrates essential proteatostatic events such as proper protein-protein interactions, protein translocation and secretion [10]. Moreover, GRP75, which is essential for proper functioning of the mitochondrial ATPase, acts as a member of the mitochondrial quality control system regulating mitophagy and apoptosis [11] and has been implicated in the inhibition of apoptosis by associating with and inactivating p53 [12]. Equally important, HSC70, a member of the HSP70 family of chaperones, participates in ER and mitochondrial stress responses while synchronising proper protein folding, clathrin-mediated translocation and autophagy [13].

Given the dubious role of glutamate in autophagy regulation, it could be speculated that stimulation of cells with this essential amino acid could lead to either apoptosis or cell survival depending on the activation status of the autophagic mechanism. To this end, the present study investigates a possible alternative role for glutamate in neural cell physiology and provides data in support of a non-apoptotic, autophagy-related mechanism induced by doses of glutamate as low as $10 \mu \mathrm{M}$.

\section{Materials and Methods}

\section{Cell Culture and treatment}

All experiments were performed with rat pheochromocytoma PC12 cells, a generous gift from I. Papamatheakis (Institute of Molecular Biology and Biotechnology, Foundation of Research and Technology, Heraklion Crete, Greece). The cells were cultured at $37^{\circ} \mathrm{C}$ in an incubator offering a humidified atmosphere of $5 \% \mathrm{CO}_{2}$ and atmospheric oxygen concentrations. The model of excitotoxicity employed utilised the exposure of PC12 cells to $10 \mu \mathrm{M}$ glutamate in low glucose complete Modified Eagle Medium supplemented with $15 \%$ horse serum, $2.5 \%$ fetal bovine serum and antibiotics. The same conditions were replicated for control cells, minus the addition of glutamate. Cells were collected at various time points after the addition of glutamate depending on the assay and washed three times in 1x PBS. Cells were then lysed and the lysate was subjected to various assays, as indicated in the figures. 


\section{Cellular Physiology Cell Physiol Biochem 2015;37:1750-1758 \begin{tabular}{l|l} 
and Biochemistry Published online: November 13, 2015 & $\begin{array}{l}\text { C) 2015 S. Karger AG, Basel } \\
\text { www.karger.com/cpb }\end{array}$ \\
\hline
\end{tabular} \\ Stamoula et al.: Glutamate Release and Autophagy}

Protein isolation, quantification and immunoblotting

Cell lysis and protein isolation was performed using the NucleoSpin TriPrep kit (Macherey-Nagel) and protein concentration was calculated using the protein quantification assay (Macherey-Nagel 740967). Electrophoresis was carried out on 10\% SDS polyacrylamide gel in a Mini-PROTEAN@ Tetra Cell (Biorad) and immunoblotting was performed in a Mini Trans-Blot ${ }^{\circ}$ Cell (Biorad) for 90 minutes at $350 \mathrm{~mA}$. Prestained Nippon Genetics (MWP02) was used as a molecular marker. Proteins were transferred on PVDF membrane (Perkin Elmer NEF1002001PK) followed by blocking with Blotto Non-Fat Dry Milk (Santa Cruz Biotechnology, sc-2324) and probing with primary antibodies. Primary antibodies $\alpha$-GRP75 (H-155) sc13967, $\alpha$-GRP78 (H-129) sc-13968 and $\alpha$-GRP-94 sc-11402 (H-212) were used at a 1:1000 dilution (Santa Cruz Biotechnology INC). Anti-HSC70 mouse IgG (AM03141PUN) and $\alpha$-b-actin mouse IgG (AM0194PN) were purchased from Acris Antibodies and used at final dilutions of 1:2500 and 1:1000, respectively. AntiGAPDH ABS16 was used at a 1:3000 dilution (Millipore). Anti-LC3 II D11 was purchased by Cell Signalling (3868) and used at a 1:1000 dilution. Goat anti-Rabbit IgG peroxidase AP132P was used at a 1:10000 dilution (Millipore) and goat anti-mouse IgG peroxidase A2554 at a 1:20000 dilution (Sigma Aldrich) as secondary antibodies. Signal detection took place using the Lumisensor reagent (Genescript, L00221V300) and Super RX films (Fujifilm, 4741008379). Image density analysis was performed with Image J software.

mRNA isolation and Real-Time PCR

Following the treatment of PC12 cells with $10 \mu \mathrm{M}$ glutamate for 30 minutes or one hour, mRNA was isolated with the NucleoSpin TriPrep kit and $1 \mu \mathrm{g}$ RNA was used as template for cDNA synthesis using the M-MLV reverse transcriptase and random primers (Promega, M1701, C1181). Real-Time PCR was carried out in duplicate using KAPA SYBR Fast ${ }^{\circledR}$ Mix (KK4603 Kapa Biosystems) in StepOne ${ }^{\mathrm{TM}}$ (Applied Biosystems). The PCR specifications were as follows: $95^{\circ} \mathrm{C}$ for 10 minutes, 40 cycles of $95^{\circ} \mathrm{C}, 60^{\circ} \mathrm{C}$ and $72^{\circ} \mathrm{C}$ for 30 seconds each, followed by a melting curve stage comprised of $95^{\circ} \mathrm{C}, 60^{\circ} \mathrm{C}$ and $95^{\circ} \mathrm{C}$ steps. The primers used were provided by Invitrogen, with the following sequences: F: 5'-AGA CCT TCA ACA CCC CAG CCA-3' and R: 5'-ATG GGC ACA GTG TGG GTG ACC-3' for b-actin, F: 5'-ACG GGA AGC TCA CTG GCA TGG-3' and R: 5'- CGC CTG CTT CAC CAC CTT CTT-3' for GAPDH, F: 5'-GCA CCC AGG CCA GTA TTG AGA-3' and R: 5'-CCA CGG AAC AGG TCA GCA TTC-3' for HSC70, F: 5'-TCC TGG AAA TTC AGA AAG GAG-3' and R: 5'-TCT GAA GTG CCA TGT TGT CTT-3' for GRP75, F: 5'-AAG AGT TCT TCA ATG GCA AGG-3' and R: 5'-GTC ATG ACA CCT CCC ACA GTT-3' for GRP78 and F: 5'-CAA GCT TGG TGT GAT TGA AGA-3' and R: 5'-GAC CCA GCC ATG AAG TAG ATT-3' for GRP94. All primers were designed to anneal to both human and rat sequences and their specificity was assessed using the NCBI BLAST software. B-actin was used as an internal control.

\section{Haematoxylin/Eosin Staining}

Following treatment with glutamate, cells were fixed in alcohol and then rehydrated by immersion in distilled water for 30 seconds with agitation; the slides were immediately dipped in a Coplin jar and incubated in Mayer's haematoxylin for 30 seconds with agitation. The samples were then rinsed 2-3 times in distilled water and subsequently stained with $1 \%$ eosin Y solution for approximately 30 seconds with agitation. Next, the sections were dehydrated with incubation twice in $95 \%$ ethanol and twice in $100 \%$ ethanol for 30 seconds each and the ethanol was extracted with two changes of xylene. Cells were finally mounted with glycerol, covered with coverslips and examined under an optical microscope.

\section{Electron Microscopy}

Following trypsinisation, cells were briefly centrifuged and the cell pellets were fixed with dropwise addition of $3 \%$ glutaraldehyde in $0.1 \mathrm{M} 1 \mathrm{x}$ PBS for 2 hours. The samples were subsequently washed in $1 \mathrm{x}$ PBS, post-fixed in $1 \%$ osmium tetroxide, rinsed with double-distilled water and finally stained in $1 \%$ uranyl acetate for 10-20 hours. The specimens were then ethanol-dehydrated and embedded in Epon 812. Semithin sections were stained with toluidine blue and observed under the light microscope in order to select areas for ultrathin sections which were stained with lead citrate and viewed under a Jeol Transmission Electron Microscope.

\section{Statistical analysis}

Graphs were created and statistical analysis of all data was performed with GraphPad Prism 5 software. Unpaired t-test was used for RT-PCR and MTT analysis between each time point and the relative untreated 


\section{Cellular Physiology Cell Physiol Biochem 2015;37:1750-1758 \begin{tabular}{l|l} 
and Biochemistry Published online: November 13, 2015 & $\begin{array}{l}\text { DO 2015 S. Karger AG, Basel } \\
\text { www.karger.com/cpb }\end{array}$ \\
\hline
\end{tabular}

control. All experiments were carried out at least three times. Data are presented as mean +/- SEM. Asterisks indicate statistical significance at $\left.\mathrm{p}<0.01{ }^{* *}\right)$ and at $\mathrm{p}<0.001\left(^{* * *}\right)$.

MTT assay

Cell viability was evaluated by the 3-(4,5-dimethyl-thiazoyl)-2,5-diphenyl-SH-tetrazolium bromide assay (MTT, Sigma-Aldrich) as originally described by Mosmann [14] and reproduced by Kritis et al. [15]; this was complemented with the Trypan Blue exclusion assay, which was clearly described by Strober [16]. Briefly, MTT was dissolved in MEM without phenol red at a final concentration of $5 \mathrm{mg} / \mathrm{ml}$, and served as a stock solution. PC12 cells exposed to excitotoxicity were further incubated for $24 \mathrm{~h}$ with $1 \mathrm{mg} / \mathrm{ml} \mathrm{MTT}$ at $5 \% \mathrm{CO}_{2}$ at $37^{\circ} \mathrm{C}$ in a humidified incubator. At the end of the incubation period, MTT formazan crystals were solubilised with $0.1 \mathrm{~N} \mathrm{HCl}$ isopropanol and absorption was detected at $570 \mathrm{~nm}$, with background subtraction at $630 \mathrm{~nm}$, using a micro-plate reader (Stat Fax - 2100, Awareness Technology Inc. USA).

\section{Results}

Low dose glutamate alters protein expression level of GRP78, GRP94, GRP75, HSC70 and GAPDH

Primary data from our laboratory that will be presented elsewhere supported a regulatory effect of glutamate on specific proteins detected with a 2D electrophoresis/mass spectrometry proteomic analysis. In order to verify these observations, PC12 cells were treated with $10 \mu \mathrm{M}$ glutamate for three hours and protein levels of GRP78, GRP94, GRP75, HSC70, and GAPDH were monitored with immunoblotting. Figure 1 shows that HSC70 and GRP78 were gradually up-regulated and peaked two hours after stimulation, while their levels subsequently subsided. GRP94 showed similar kinetics with a slower but steadier increase, while GAPDH levels showed a slight reduction and GRP75 levels rapidly decreased and remained low throughout the duration of the treatment.

Effect of low dose glutamate administration on mRNA levels of GRP78, GRP94, GRP75, HSC7O and GAPDH

In order to check whether the observed changes in the protein levels follow a concomitant transcriptional deregulation of the molecules investigated, RNA was extracted from PC12 cells treated with $10 \mu \mathrm{M}$ glutamate for 30 minutes or 1 hour and the mRNA levels of GRP78, GRP94, GRP75, HSC70 and GAPDH were calculated with qRT-PCR. Interestingly, whereas GAPDH and GRP75 showed no significant changes, GRP78, HSC70 and GRP94 showed reduced mRNA levels upon treatment with glutamate (Fig. 2), thus excluding the possibility that the alterations seen in the protein levels of these three molecules reflected enhanced transcriptional activity.

Treatment of PC12 cells with low amounts of glutamate triggers an autophagic response

In order to check whether there is a phenotypic outcome of low dose glutamate, PC12 cells were treated with $10 \mu \mathrm{M}$ of the amino acid for three hours and subsequently stained with Haematoxylin/Eosin. Figure 3 shows increased acidification and cytoplasmic condensation as well as the presence of ghost cells (not actively metabolising cytoplasm), which is indicative of degeneration and autophagy-associated cell death. However, control cells treated with empty vehicle grew normally and did not show any significant morphological changes. In depth analysis of the glutamate effect on PC12 physiology with electron microscopy (Fig. 4) supported an autophagic phenotype with overt disorganisation and vacuolisation of the endoplasmic reticulum that promotes vesicular cytoplasmic degeneration and condensed irregularly-shaped nuclei. Induction of an autophagic response was further underlined through the up-regulation of LC3 II, used here as an autophagic marker.

Glutamate concentration sets the threshold of excitotoxicity induced cell death

Having shown that the treatment of PC12 cells with glutamate alters the expression of several chaperones and triggers an autophagic response, we then asked whether there was 
Fig. 1. The effect of glutamate on expression of HSC70, GRP75, GRP78, GRP94 and GAPDH of extracts.

Representative western blots. (B) Quantitation of the protein levels relative to b-actin. Untreated samples were given the arbitrary value of ' 1 '. The figure shows the median of three experiments +/- SEM. PC12 protein

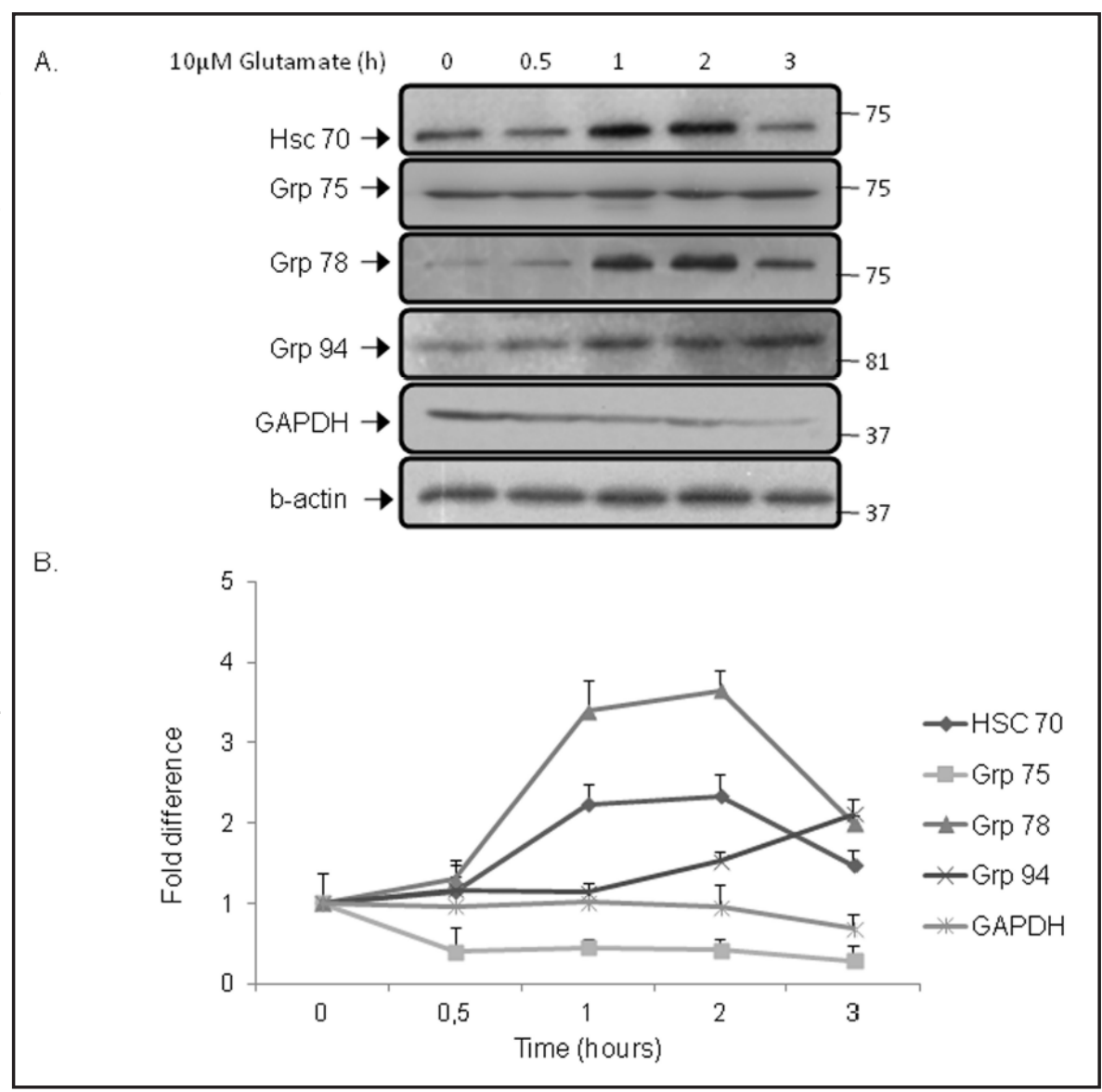

Fig. 2. mRNA expression levels of HSC70, GRP75, GRP78, GRP94 and GAPDH following glutamate treatment of PC12 cells. Relative expression analysis was achieved with the $2^{-\Delta \Delta \mathrm{Ct}}$ method. All values were normalised to untreated samples and b-actin was used as internal control. The figure shows the median of three experiments +/- SEM. Three asterisks (***) denote $\mathrm{p}<0.001$. $\mathrm{N}=3$.

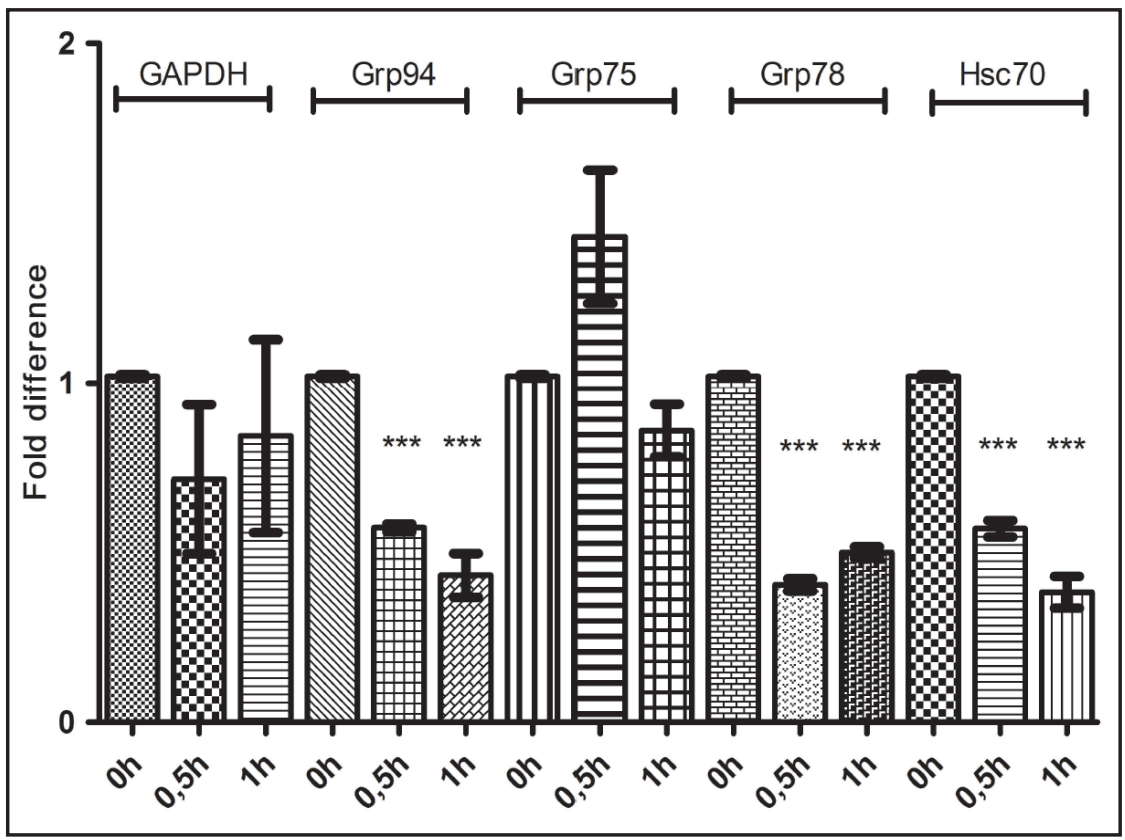

a direct effect on cell survival. To answer this question we performed MTT assays on PC12 cells treated with various concentrations of glutamate for 24 hours (Fig. 5). Apparently, low doses of glutamate that fit our findings up to this point (Fig 1-4) showed a pro-survival rather a pro-apoptotic effect. However, increasing amounts of the amino acid reduce the survival 
Fig. 3. Glutamateinduced morphological changes on PC12 cells after staining with $\mathrm{H} \& \mathrm{E}$. (A) PC12 cells cultured in normoxic conditions.

PC12 cells cultured in the presence of $10 \mu \mathrm{M}$ glutamate for 3 hours.

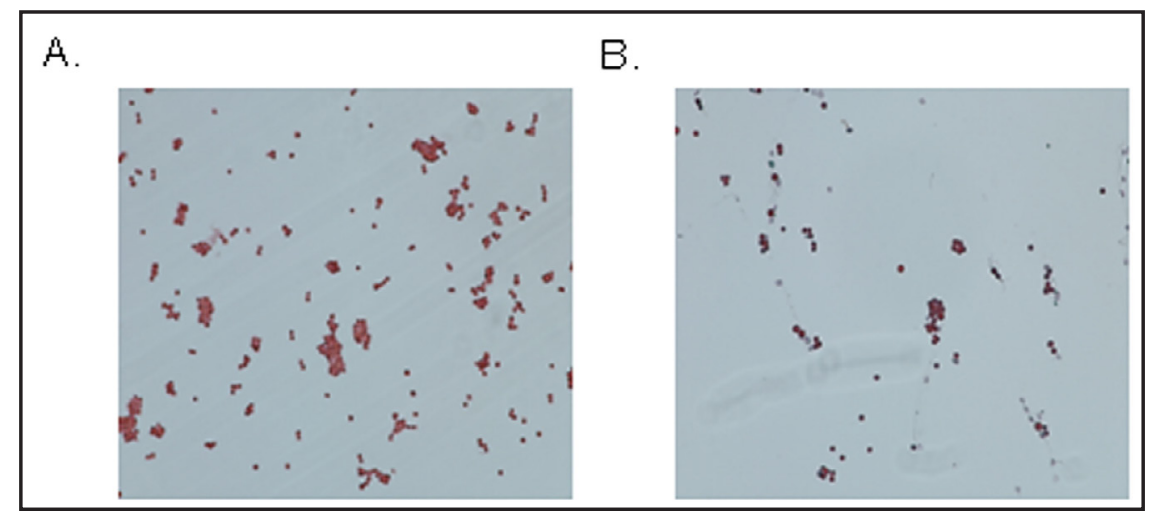

Fig. 4. Low amounts of glutamate induce autophagy in PC12 cells. Representative cell images captured with electron microscopy (a) under normal culture conditions or (b) under treatment with $10 \mu \mathrm{M}$ glutamate for 3 hours. (c) Representative western blot of LC3 II protein levels following glutamate treatment of PC12 cells for the indicated time points.

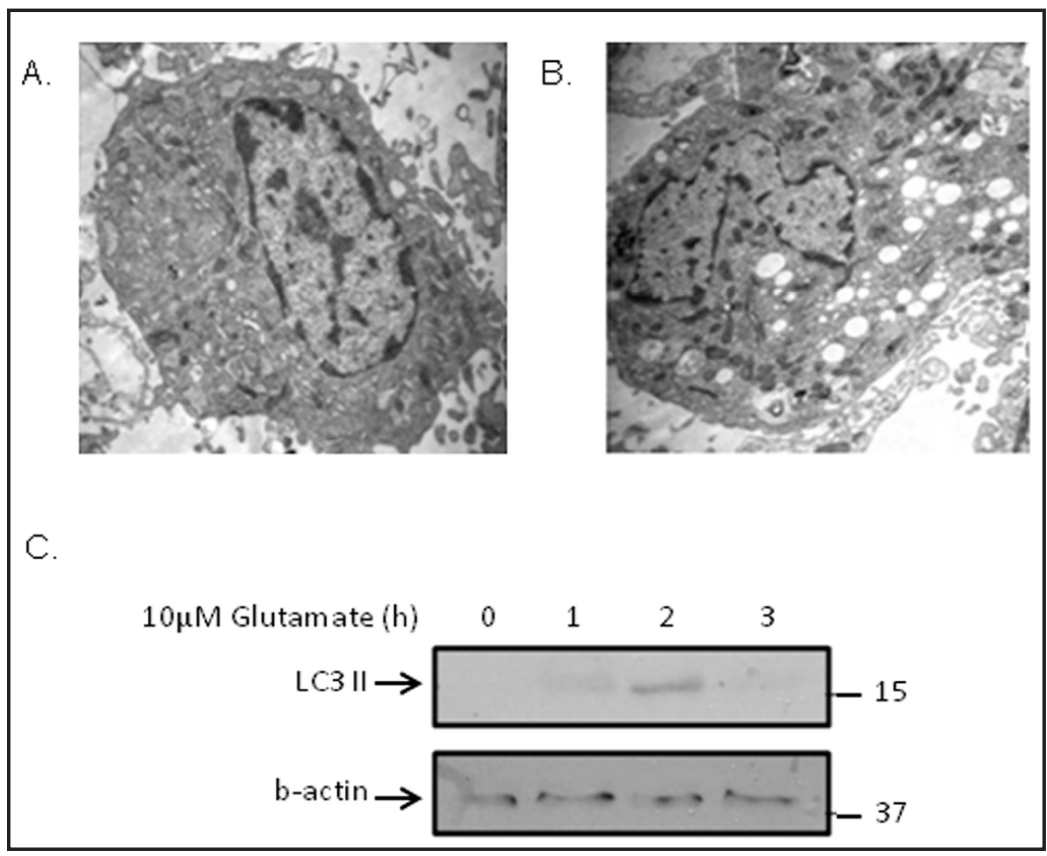

Fig. 5. The dose-dependent effect of glutamate on PC12 survival. Increasing amounts of glutamate decrease the survival threshold of PC12 cells. Statistical analysis was performed with unpaired t-test ${ }^{* *} \mathrm{p}<0.01$, ${ }^{* * *} \mathrm{p}<0.001$ ). The figure shows the median of three experiments +/- SEM.

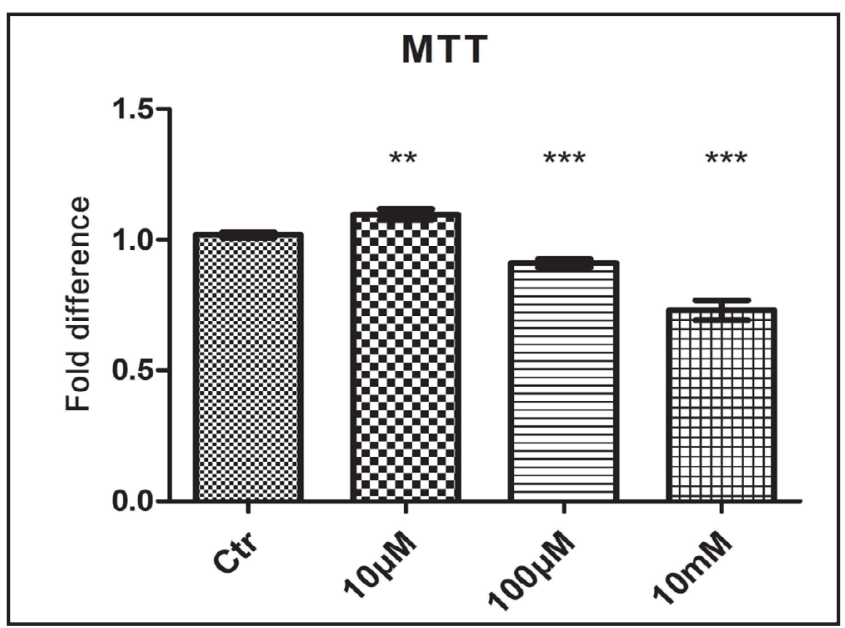

rate in a dose-dependent trend supporting thus the existence of a concentration threshold for glutamate above which the amino acid is highly toxic for the cells.

\section{KARGER}




\section{Cellular Physiology Cell Physiol Biochem 2015;37:1750-1758 \begin{tabular}{l|l} 
and Biochemistry Published online: November 13, 2015 & $\begin{array}{l}\text { DO 2015 S. Karger AG, Basel } \\
\text { www.karger.com/cpb }\end{array}$ \\
\hline
\end{tabular} \\ Stamoula et al.: Glutamate Release and Autophagy}

\section{Discussion}

In the Central Nervous System (CNS), glutamate is a major neurotransmitter playing a crucial role in the proper function of neuronal transmission and cell communication. On the other hand, glutamate is an important factor involved in many neurodegenerative diseases acting as a neurotoxin that leads to excitotoxicity and increased intracellular calcium influx [6].

In this work we investigated the impact of low dose glutamate administration on PC12 pheochromocytoma cells. Our results (Fig. 5) show that treatment with glutamate at final concentration as high as $10 \mathrm{mM}$ reduced cell viability in total agreement with previously published data [17]. To our surprise however, lower amounts of the amino acid did not support a pro-apoptotic role for glutamate and this led us to speculate that there might be a concentration threshold that triggers glutamate-induced cytotoxicity. Morphological analysis of PC12 cells treated with low amounts of glutamate $(10 \mu \mathrm{M})$ revealed ghost cells indicative of autophagic process (Fig. 3). This observation was further verified by electron microscopy that showed disorganized endoplasmic reticulum and vesicular cytoplasmic degeneration. Moreover, immunoblotting of LC3 II, used here as an autophagosome marker, shows elevated levels (Fig. 4) which is a common feature of autophagic responses [18]. Overall, the results support the notion that in the presence of low amounts of glutamate, cells undergo an autophagic pro-survival procedure. This may reflect the fact that under mild stress conditions cells may develop an autophagic reaction, which in turn selectively removes damaged organelles as a cytoprotective mechanism [19]. Alternatively, prolonged or and/or enhanced stimulation of the cells with glutamate could lead progressively to cell death either through apoptosis or another death mechanism [20]. Conclusively, the final outcome of glutamate activity is highly depended on its concentration as well as the duration of its action and this observation follows a global pattern of glutamate-related signalling outcomes as recently reviewed in [21].

In support of previous unpublished data from our laboratory, treatment of PC12 cells with low amounts of glutamate alters the protein levels of various GRPs and HSC70 underlying thus a specific signature of chaperone expression (Fig. 1). Interestingly enough, a similar expression pattern was also evidenced under hypoglycaemia-induced stress [22] which leads to the hypothesis that these chaperones may act in a global fashion under different kinds of stress to dictate the response of a cell depending on the potential of the external stimulus. A more detailed analysis of the data shows an up-regulation of GRP78, HSC70 and GRP94. This supports the induction of a chaperone-mediated neuroprotective mechanism since all these proteins enhance cell viability $[23,24]$. The observed expression profile of these chaperones however, may be context-depended since it has been found that upregulation of GRP78 for example is associated with enhanced ER stress and cell death in isoprotenerol-induced cardiomyocyte hypertrophy [25] or under cold stress [26]. On the other hand, chaperones such as GRP75 act constantly in favour of stress-induced cell death and their downregulation such as in our case is directly connected to cell survival [11]. Finally, GAPDH that can also trigger a death signal cascade in cells undergoing stress shows a relatively low reduction in expression [27]. Conclusively, our data support a chaperonemediated autophagic mechanism induced by low amounts of glutamate that acts in favour of cell survival.

An interesting finding in the present study is also the fact that GRP78, HSC70 and GRP94 protein up-regulation does not coincide with their mRNA levels, which follow opposite kinetics (Fig. 2). This comes as no surprise, as glutamate can induce an endoplasmic reticulum stress-associated death signalling cascade in neuronal cells [28] resembling the unfolded protein response known to promote a global transcriptional reprogramming [29]. The particular finding also supports the speculation that the observed up-regulation in protein levels of these chaperones is caused probably by post-translational modifications known to block protein turnover and promote protein stability, such as ubiquitination [30], which needs further investigation. 
In conclusion, our findings support a novel role for glutamate, an amino acid known mainly for its participation in excitotoxicity-associated mechanisms. We demonstrate in the present study that minor augmentation in the concentration of glutamate drives a cytoprotective mechanism in neuronal cells. Based on our data, this is achieved through the deferential regulation of various chaperones that orchestrate an autophagic response supporting cell survival.

\section{Abbreviations}

UPR (Unfolded Protein Response); ER(Endoplasmic Reticulum); GRP78 (Glucose Regulated Protein 78); GRP94 (Glucose Regulated Protein 94); HSC70 (Heat Shock Cognate protein 70); HSP90 (Heat shock Protein 90); LC3 (Microtubule-associated protein 1A/1Blight chain 3); GAPDH (Glyceraldehyde 3-phosphate dehydrogenase); NO (Nitric Oxide); MTT (3-(4,5-dimethylthiazol-2-yl)-2,5-diphenyltetrazolium bromide); qRT-PCR (quantitative Real Time Polymerase Chain Reaction).

\section{Acknowledgement}

The present work was supported by the Program for Basic Research Activity Enhancement of the Research Committee of Aristotle University (project number 89337), European Union/European Social Fund EPEAEK PYTHGORAS II (project number 13) as well as the yearly Laboratory of Physiology fund allocation. No additional funding was received for this study. The funders had no role in study design, data collection and analysis, decision to publish, or preparation of the manuscript.

\section{Disclosure Statement}

The authors declare there are no conflicts of interest.

\section{References}

1 Platt SR: The role of glutamate in central nervous system health and disease--a review. Vet J 2007;173:278286.

2 Peng S, Zhang Y, Zhang J, Wang H, Ren B: Glutamate receptors and signal transduction in learning and memory. Mol Biol Rep 2011;38:453-460.

3 Dong XX, Wang Y, Qin ZH: Molecular mechanisms of excitotoxicity and their relevance to pathogenesis of neurodegenerative diseases. Acta Pharmacol Sin 2009;30:379-387.

$4 \quad$ Lau A, Tymianski M: Glutamate receptors, neurotoxicity and neurodegeneration. Pflugers Arch 2010;460:525-542.

5 Schubert D, Piasecki D: Oxidative glutamate toxicity can be a component of the excitotoxicity cascade. J Neurosci 2001;21:7455-7462.

6 Mehta A, Prabhakar M, Kumar P, Deshmukh R, Sharma PL: Excitotoxicity: bridge to various triggers in neurodegenerative disorders. Eur J Pharmacol 2013;698:6-18.

7 Sokka AL, Putkonen N, Mudo G, Pryazhnikov E, Reijonen S, Khiroug L, Belluardo N, Lindholm D, Korhonen L: Endoplasmic reticulum stress inhibition protects against excitotoxic neuronal injury in the rat brain. J Neurosci 2007;27:901-908. 


\section{Cellular Physiology Cell Physiol Biochem 2015;37:1750-1758 \begin{tabular}{l|l|l} 
DOI: 10.1159/000430250 & (C) 2015 S. Karger AG, Basel
\end{tabular}

8 Hetz C, Mollereau B: Disturbance of endoplasmic reticulum proteostasis in neurodegenerative diseases. Nat Rev Neurosci 2014;15:233-249.

9 Song L, Liu H, Ma L, Zhang X, Jiang Z, Jiang C: Inhibition of autophagy by 3-MA enhances endoplasmic reticulum stress-induced apoptosis in human nasopharyngeal carcinoma cells. Oncol Lett 2013;6:10311038.

10 Gutierrez T, Simmen T: Endoplasmic reticulum chaperones and oxidoreductases: critical regulators of tumor cell survival and immunorecognition. Front Oncol 2014;4:291.

11 Burbulla LF, Fitzgerald JC, Stegen K, Westermeier J, Thost AK, Kato H, Mokranjac D, Sauerwald J, Martins LM, Woitalla D, Rapaport D, Riess O, Proikas-Cezanne T, Rasse TM, Kruger R: Mitochondrial proteolytic stress induced by loss of mortalin function is rescued by Parkin and PINK1. Cell Death Dis 2014;5:e1180.

12 Kaul SC, Aida S, Yaguchi T, Kaur K, Wadhwa R: Activation of wild type p53 function by its mortalin-binding, cytoplasmically localizing carboxyl terminus peptides. J Biol Chem 2005;280:39373-39379.

13 Stricher F, Macri C, Ruff M, Muller S: HSPA8/HSC70 chaperone protein: structure, function, and chemical targeting. Autophagy 2013;9:1937-1954.

14 Mosmann T: Rapid colorimetric assay for cellular growth and survival: application to proliferation and cytotoxicity assays. J Immunol Methods 1983;65:55-63.

15 Kritis A, Pourzitaki C, Klagas I, Chourdakis M, Albani M: Proteases inhibition assessment on PC12 and NGF treated cells after oxygen and glucose deprivation reveals a distinct role for aspartyl proteases. PLoS One 2011;6:e25950.

16 Strober W: Trypan blue exclusion test of cell viability. Curr Protoc Immunol 2001;Appendix 3:Appendix 3B.

17 Pereira CF, Oliveira CR: Oxidative glutamate toxicity involves mitochondrial dysfunction and perturbation of intracellular Ca2+ homeostasis. Neurosci Res 2000;37:227-236.

18 Kumari S, Mehta SL, Li PA: Glutamate induces mitochondrial dynamic imbalance and autophagy activation: preventive effects of selenium. PLoS One 2012;7:e39382.

19 Kim I, Rodriguez-Enriquez S, Lemasters JJ: Selective degradation of mitochondria by mitophagy. Arch Biochem Biophys 2007;462:245-253.

20 Puyal J, Ginet V, Clarke PG: Multiple interacting cell death mechanisms in the mediation of excitotoxicity and ischemic brain damage: a challenge for neuroprotection. Prog Neurobiol 2013;105:24-48.

21 Kritis AA, Stamoula EG, Paniskaki KA, Vavilis TD: Researching glutamate - induced cytotoxicity in different cell lines: a comparative/collective analysis/study. Front Cell Neurosci 2015;9:91.

22 Cavaliere F, D’Ambrosi N, Sancesario G, Bernardi G, Volonte C: Hypoglycaemia-induced cell death: features of neuroprotection by the P2 receptor antagonist basilen blue. Neurochem Int 2001;38:199-207.

23 Avila MF, Cabezas R, Torrente D, Gonzalez J, Morales L, Alvarez L, Capani F, Barreto GE: Novel interactions of GRP78: UPR and estrogen responses in the brain. Cell Biol Int 2013;37:521-532.

24 Shimura H, Schwartz D, Gygi SP, Kosik KS: CHIP-Hsc70 complex ubiquitinates phosphorylated tau and enhances cell survival. J Biol Chem 2004;279:4869-4876.

25 Lin Y, Zhang X, Wang L, Zhao Y, Li H, Xiao W, Xu C, Liu J: Polyamine depletion attenuates isoproterenolinduced hypertrophy and endoplasmic reticulum stress in cardiomyocytes. Cell Physiol Biochem 2014;34:1455-1465.

26 Dai MX, Zheng XH, Yu J, Yin T, Ma MJ, Zhang L, Liu M, Ma Y, Liu LW, Gao X, Li Y, Song LQ, Wang HC: The impact of intermittent and repetitive cold stress exposure on endoplasmic reticulum stress and instability of atherosclerotic plaques. Cell Physiol Biochem 2014;34:393-404.

27 Hara MR, Thomas B, Cascio MB, Bae BI, Hester LD, Dawson VL, Dawson TM, Sawa A, Snyder SH: Neuroprotection by pharmacologic blockade of the GAPDH death cascade. Proc Natl Acad Sci U S A 2006;103:3887-3889.

28 Jin ML, Park SY, Kim YH, Oh JI, Lee SJ, Park G: The neuroprotective effects of cordycepin inhibit glutamateinduced oxidative and ER stress-associated apoptosis in hippocampal HT22 cells. Neurotoxicology 2014;41:102-111.

29 Arensdorf AM, Diedrichs D, Rutkowski DT: Regulation of the transcriptome by ER stress: non-canonical mechanisms and physiological consequences. Front Genet 2013;4:256.

30 Atkin G, Paulson H: Ubiquitin pathways in neurodegenerative disease. Front Mol Neurosci 2014;7:63. 